\title{
A Process Description of Playing to Live! A Community Psychosocial Arts Program During Ebola
}

\author{
C. Alexis Decosimo \\ Playing to Live! and East Tennessee State University \\ Jessi E. Hanson \\ Playing to Live! and University of Pittsburgh \\ Catherine R. Boland \\ Playing to Live! \\ Deborah Slawson \\ East Tennessee State University \\ Mary Ann Littleton \\ East Tennessee State University \\ Megan Quinn \\ East Tennessee State University
}

From 2014 to 2015, Liberia experienced the largest Ebola epidemic in world history. The impact of this disease was not only physical; it created fear, loss, and trauma throughout the country. This article will describe the process of three phases of a community-based psychosocial expressive arts program, which used theory from the fields of expressive arts therapy to build mental health capacity during and after the epidemic. This article will highlight the background of Ebola virus disease and the Ebola virus disease epidemic, provide an overview of current theory and research for expressive arts therapy and the impact of trauma, describe the process of how the program developed and was implemented, the process of partnering with the community, program components, the two pilot programs, and the large-scale community program. We performed a mixed-methods analysis of the large-scale program's activity data to evaluate the impact. The results highlight a positive response from the participating children and facilitators. The authors discuss the findings from the results, best practices, and limitations. Additionally, the authors discuss implications and considerations for future programming.

Keywords: expressive arts, community-based program, Ebola virus disease, Liberia

Playing to Live! wishes to acknowledge Ernest Garnark Smith Jr. and Prisie Badu from RESH for leading program implementation, data collection, and data sharing; as well as the Ebola Survivors' Network, the Liberian Ministry of Gender Development and the Ministry of Health for their continual guidance during the development and implementation; and UNICEF for financing this project. 


\section{Introduction}

From 2014 to 2015, West Africa experienced the largest Ebola virus disease (EVD) epidemic in world history. Liberia was the most effected country, and with its recent history of a 14-year civil war, the country had a severely weakened and limited health care system, including a significant gap in vital mental health services. The physical agony of EVD is profound; in addition, the emotional and psychological toll on the individual, family, and community is severe and long lasting.

An American-based nonprofit teamed up with Liberian government ministries and in-country organizations to develop and implement solutions to combat the vast psychological impact of EVD. This article describes the therapeutic expressive arts program developed over three separate phases, which focused on combating negative impacts of EVD. Phase 1 was implemented in an isolation center for children and facilitated by Ebola survivors. Phase 2 was based on Phase 1's program and implemented in a highly affected community. Phase 3 included a large-scale program that reached approximately 870 children, trained 40 hired female survivors of EVD, and was implemented in 40 former hot-zone communities. A mixed-method design with a delayed treatment group was implemented to evaluate Phase 3 programming. The main process data collected included 127 activity reports blindly selected from 500 total activity reports completed by trained facilitators. The activity reports were evaluated utilizing a grounded theory approach to analyze facilitator and beneficiary reactions to the programming. Themes and descriptive statistics from the activity reports are highlighted in this article. Limitations and future implications are explored following the analysis.

\section{Ebola Virus Disease and Epidemic}

The 2014-2015 West African EVD epidemic has been traced to Guinea, where it began in December 2013; to date, it is the largest EVD epidemic (Hugo et al., 2015; World Health Organization [WHO] Ebola Response Team, 2014). The WHO was notified on March 23, 2014, but a public health emergency of international concern was not declared until August 8, 2014. By then, Ebola was spreading rapidly through Guinea, Liberia, and Sierra Leone. Improper sanitation, a distrust of authority, burial practices, and limited access to hospitals played a role in the rapid spread of EVD across West Africa (Pandey et al., 2014). In September 2014, the epidemic peaked to 950 confirmed cases per week in West Africa. Between the first known case in December 2013 and April 2016, when the recovery phase began, over 28,000 cases were reported of which 11,310 resulted case fatalities (WHO Ebola Response Team, 2016).

EVD is a disease characterized by viral hemorrhagic fever with five unique strains; the Zaire strain, with a $60-90 \%$ mortality rate, has been identified as present during the recent epidemic in West Africa (Casey, 2015). In 2014, the WHO Ebola Response Team (2014) estimated a 71\% case-fatality rate in this epidemic (95\% confidence interval [69\%, 73\%]). While the initial case was likely transmitted from animal to human, all subsequent cases are thought to be from human to human contact, primarily through bodily fluids (Pandey et al., 2014). 


\section{Liberia's Mental Health System}

An estimated 200,000 people were killed and over 1 million people displaced during Liberia's 14-year civil war (Kohrt et al., 2015). Postconflict countries generally struggle with the redevelopment and establishment of order and at the same time these countries rarely come close to meeting the need to treat the major health consequences of their citizens during and following the conflict (Levey et al., 2013). Several postwar needs assessments performed in Liberia confirmed significant needs for mental health services; both a lack of trained mental health professionals and paraprofessionals were identified (Levey et al., 2013). In 2010, there was one psychiatry clinic with 67 inpatient beds and outpatient services and one psychiatrist for the whole country (Kohrt et al., 2015). In the same year, the Government of Liberia partnered with the Carter Center to direct and implement an accredited 6-month mental health training course for physician and nurses. Between 2010 and 2014, 150 health workers were certified as mental health workers through this training course (Kohrt et al., 2015). Despite the scale-up of trained physicians and nurses, an assessment of needs in Liberia completed in 2015 found that only $12 \%$ of individuals living in rural communities had access to mental health care (Kruk et al., 2015). During the Ebola epidemic, the already limited health systems began to shut down as the country's infrastructure deteriorated under the crisis (Hayden, 2014).

\section{Community-Based Participatory Research}

While research on mental health has had a primary focus on the risk factors of individuals, research has also shown that the community's risk factors have a significantly high impact on individuals (Israel, Schulz, Parker, \& Becker, 1998). Community-based participatory research (CBPR) is becoming increasingly regarded as a best practice when working with oppressed or marginalized populations (Escandón, 2014). Within this practice, the community is considered vital in each step of development, implementation, and research. CBPR is defined as, a collaborative approach, which builds equity between the community and organizations (Escandón, 2014), where the community is asked to use their roles as leaders and experts to guide the establishment of goals and outcomes for the programs and policies (Rasmus, 2014).

\section{Impact of Childhood Trauma}

Trauma is when a person has witnessed, experienced, or has had exposure to an event or multiple of events that threaten the life or integrity of the individual or others (American Psychiatric Association, 2013). The experience of a traumatic event can impact virtually every component of an individual's life, including physical and mental health, relationships, academic and economic success, personality, and quality of life. Chronic exposure to traumatic events has been considered one of the most toxic risks to a body's disease response. Disease pathogens can influence multiple systems of the body, including: behavioral, physical, and psychological responses. Trauma has been shown to shut down these systems, which make the body less resilient to fighting off diseases and infections (Cohen, Janicki-Deverts, \& Miller, 2007).

Research has shown a strong correlation between childhood posttraumatic stress disorder (PTSD) and impairment in cognitive functioning and maladaptive behaviors of a child including: erratic responses, frequent emotional outbursts, and slow cognition (Bremner et al., 1997; Briggs-Gowan et al., 2010; Van der Kolk, 1989). An increase in scholastic issues, mental illness, interpersonal issues, 
and drug abuse has also been found to strongly correlate with childhood trauma (Mouthaan et al., 2014).

Children affected by the Ebola epidemic were at high risk for developing post trauma reactions due to multiple factors. Research shows that children have a higher risk of developing posttraumatic stress disorder if they live in environments with multiple factors of adversity (Berkowitz, Stover, \& Maran, 2011), and at the time of the Ebola epidemic, Liberia was still recovering from a 14-year civil war, which left behind high rates of poverty, adversity, and fragmented families. This coupled with limited mental health capacity left children and families vulnerable to developing post trauma stress.

\section{Expressive Arts Therapy}

Expressive arts therapy refers to a group of individual mental health professions that use expressive art and play to support exploration, growth, and healing. Art therapy's theory is deeply rooted in the belief that all human beings can express their emotions and thoughts through imagery and exploration (Warson, 2012). Research supports the effectiveness of art therapy, where psychotherapy and neurobiology studies have highlighted it as a beneficial tool for trauma recovery (Gantt \& Tinnin, 2009; Talwar, 2007). During the early stages of a child's life, play is a developmentally appropriate mechanism for children to communicate and explore the world, but the experience of trauma can disrupt this developmental process on multiple levels (Banbury, 2016). Child-centered play therapy has been found to be an effective tool to combat these negative effects of childhood trauma (Gonzalez \& Bell, 2016). While children typically store trauma memories deep in their subconscious brain (Orr, 2007), the action of engaging in expressive art activities activates complex brain connections between the left and right side of the brain, which facilitates healing (Kaplan, 2000). Due to a child's limited vocabulary, art, play, and movement can help children communicate through expression, explore their grief and trauma, and explore their healing process (Coholic, Eys, \& Lougheed, 2012; Orr, 2007). Ebola caused such severe trauma experiences words could not do it all justice. By using play and art expression, children can explore their healing growth through their own imagination, interactions with peers, and support from caregivers.

\section{Playing to Live!}

Playing to Live! (PTL) is a 501(c) 3 American nonprofit organization that builds effective and sustainable community-based expressive art programs to target the psychosocial needs of children and communities facing trauma. PTL is composed of a team of expressive arts therapists, including an art therapist, play therapist, yoga therapist, and child-life specialist. These clinicians identify effective techniques and best practices from their respective fields and work together to build trainings for paraprofessionals across different settings. PTL partners with local organizations to create trauma informed psychosocial programming that is culturally relevant and works collaboratively with communities to ensure that this work is driven by community specific needs. PTL provides support, follow-up, and monitoring and evaluation to support program effectiveness and sustainability. PTL implemented three phases of therapeutic expressive arts programming in collaboration with the Liberian organizations during the 2014-2015 West Africa Ebola epidemic. 


\section{Method}

\section{Program Description}

To begin to fill the gap in mental health services in Liberia during the EVD epidemic and address the widespread community trauma due to EVD, PTL developed community-based programming rooted in the theories of expressive arts therapy. Programming was implemented during the Ebola outbreak and based on local recommendations. PTL's psychosocial expressive arts program was implemented in three phases: Phase 1, Phase 2, and Phase 3. Descriptions of the phases are included below.

Phase 1 was implemented in an Ebola quarantine center for children. The program's facilitators were nine female and three male Ebola survivors. These individuals were contracted by the Ministry of Health and Social Welfare (MOHSW) to be voluntary caregivers, whose role was to tend and monitor the children. Approximately 30 children, ages $3-19$, received the programming during their 21-day stay.

Phase 2 was a community-based pilot program implemented in one of the highest Ebola-affected communities near Monrovia, Liberia. Approximately 60 children were active participants during the 6-month implementation.

Phase 3 was a large-scale community-based program adapted from Phases 1 and 2 and consisted of two treatment groups. Treatment Group 1 (TG1) was implemented for 5 months, and Treatment Group 2 (TG2) began 2 months after TG1 and lasted 3 months.

\section{Phase 1: Pilot Program}

In October 2014, PTL was founded as a response to the recognition that a mental health crisis was happening alongside the physical epidemic of EVD. The cofounder of the organization traveled to Monrovia to advocate for the necessity of a mental health program aimed to combat the psychological trauma of Ebola. This team member performed a rapid needs assessment, identified site location and program participants, and developed and implemented programming. Below is a breakdown of these three steps.

\section{Rapid Needs Assessment}

The rapid needs assessment included three key goals: (a) to complete a stakeholder analysis and identify potential partner organization for program implementation, (b) identify and select project beneficiaries, and (c) evaluate potential project settings and locations. To complete this work, the cofounder contacted past colleagues currently working in Liberia, visited EVD treatment units (ETUs) and quarantine centers, and spoke with various nonprofits operating on the ground. Both PTL's founder and cofounder previously worked in Liberia, which acted as an advantage to access key stakeholders. At this time, most nongovernment organizations (NGOs) were international organizations and were transitioning their staff and programming to respond to the crisis. During this time, the cofounder consistently attended EVD coordination meetings to keep updated on the crisis, to make contact and build relationships with the proper state ministry agencies, and assess the crisis needs and seek opportunities for project piloting. With the goal of building a partnership with the MOHSW and Ministry of Gender Development (MOGD), the PTL cofounder attended all available meetings, adhered to set protocols placed by the Ministries, and built relationships with 
stakeholders by extending voluntary support to needs outside of PTL programming, such as helping coordinate the development of child tracking forms and data entry. These steps highlight one of PTL's core values which are to design each project in coordination with key stakeholders and the official protocols suggested by the government leadership.

\section{Program Location and Participants}

Within a week, the MOHSW and the primary organization running the interim care center (ICC) provided permission for PTL to enter and assess the ICC for children exposed to EVD but not yet demonstrating symptoms. EVD adult survivors were assigned as the caregivers to the children. Each caregiver had recently been discharged from an ETU, often having lost many family and community members. They reported feeling overtired, depressed, and overwhelmed. The MOHSW hired them to work for international NGOs operating in ETUs and ICCs temporarily as they were the best frontline workers, who were thought to have developed some immunity to the disease, and often jobless due to the stigma around their disease status.

The initial plan was to train local clinicians to conduct programs in the quarantine center. However, clinicians were not willing to work in the high-risk conditions, so PTL modified its plan, which was based on MOHSW suggestion, to train the ICC caregivers. Due to working in a high-risk environment, the PTL cofounder, whose role was to act as a trainer, followed the safety protocols within the ICC to minimize transmission risks.

\section{Training Model}

PTL used a train-the-trainer method, teaching the ICC caregivers to become trained PTL facilitators. Before implementing the train-the-trainer model, the PTL trainer identified the resources and activity needs of the ICC, the capacity of the caregivers, and the ages and social skills of the children housed inside. This information was reported to the PTL clinical team of expressive art therapists in the United States to develop the first set of activities for the children. The training program was derived from best practices from the expressive arts therapy fields represented by the clinicians and consisted of 25 expressive arts activities aimed to decrease psychological stress for the children. The activities focused on helping children build healthy relationships, self-esteem, emotional communication, a concept of safety, and learn coping skills.

Over the length of the pilot, the PTL trainer worked directly in the ICC and implemented two to four activities per day while conducting training and mentorship to the caregivers. Additionally, following the theory of CBPR, PTL valued the opinions and needs of the facilitators, families, caregivers, and children and incorporated their feedback (Escandón, 2014).

\section{Program Components}

In a span of 6 weeks, the following program components were completed: (a) the program was designed by the clinical team; (b) a pilot program was tested with four to 10 ICC children per activity by the PTL trainer and ICC caregivers; (c) documented feedback from the caregivers and the PTL trainer was provided to the PTL clinicians; (d) after implementing feedback, the training and compiled activity guide was finalized, reviewed, and critiqued in a workshop held by a team of 10 Liberian experts representing multiple organizations, the two Liberian ministries, and two caregivers for cultural relevance, language, and child protection protocol adhering to newly set standards for EVD prevention; (e) the program was finalized by the clinical team with the provided feedback, and a final activity guidebook was approved by the MOHSW's psychosocial pillar and the MOHSW/MOGD child protection division. 
After the curriculum was approved, the ICC caregivers were formally trained on how to conduct PTL activities on their own, with monitoring support by the PTL trainer, all of which included basic techniques on how to use art, play, and yoga to teach the children coping skills, emotional communication, relationship building, and other basic techniques to combat the effects of childhood trauma. Phase 1 lasted for 6 weeks; the caregivers continued to use activities for the following 4 months until the ICC closed.

\section{Pilot Program Outcomes}

When PTL began in the ICC, the Ebola survivor caregivers were exhausted, grieving, and overwhelmed with taking care of the children. They also experienced a high amount of trauma due to being survivors of Ebola themselves and most reported losing over 50\% of their immediate family to the virus. They were at first skeptical of PTL and resistant to adding another responsibility for themselves. PTL's program manager did not push the program and she trained one caregiver who was willing. Over a short time, the other caregivers saw the benefit the program was having on the children. The children were laughing more, building relationships, and expressing their emotions through play and art. Soon they asked to be trained in PTL. While we knew the benefits of our programming as clinicians, we valued the resistance of the caregivers and did not pressure them to be involved with our programming. This provided an opportunity for PTL to communicate to the caregivers that their opinion and needs mattered, and they had the choice to participate or not.

\section{Phase 2: Pilot Program in the Community}

Following the implementation of Phase 1, the MOHSW/MOGD invited PTL to build programming in two identified communities, both of which were considered to be in the highest affected hot zone areas in Montserrado County in Liberia. Of the two identified communities, one program implementation took place in a care center for children orphaned by EVD, and the second program implementation took place in a semiurban community. This community had the most documented deaths of EVD in 2014. During Phase 2, there were 60 child participants, and the project was extended to support parents and legal guardians of the participants to facilitate their ability to support the child's emotional stress. PTL trained and hired two Liberian PTL staff, who implemented the community program and acted as PTL representatives at MOHSW/MOGD meetings. Liberian PTL staff included a project director with training in psychology and child welfare, and a project associate, a female EVD survivor trained in nursing, who worked under the mentorship of the trained Liberian clinician and manager of the organization.

In December 2014, PTL partnered with a local Liberian NGO, Renewed Energy Serving Humanity (RESH), to assist in implementing this community-based program and identify grant opportunities. RESH is a Liberian nonprofit organization that trains local Liberians to implement psychosocial support within their communities. The founder of RESH is a counseling professor in Liberia and is a major advocate for the growth of mental health care in the country. An initial memorandum of understanding was drafted between PTL and RESH and sanctioned with the MOHSW.

The two Liberian PTL staff worked alongside the trained PTL ICC caregivers to review the activities and identify best practices and lessons learned. Additionally, the American PTL team conducted virtual trainings with the Liberian team on each activity. Together RESH and PTL adjusted the activities for a community setting. The RESH and PTL's two staff implemented on average two to four activities per visit and visited each site twice a week in the new community site. They underwent strict safety protocols including hand washing and wearing protective gear including but 
not limited to gloves and masks to minimize possible EVD exposure as these were active hot zone communities. MOHSW/MOGD experts monitored the monthly progress of the Liberian RESH/PTL team. The PTL project director attended all state-led psychosocial pillar meetings and submitted formal reports to the child protection division regularly, as a means of compliance and to maintain a good relationship with these in-country experts. Phase 2 lasted over 6 months and was implemented at minimal cost including: staff part-time pay, activity supplies, communication, and transportation. During this phase, the PTL program was further developed to reflect the needs, culture, and suggestions of the Liberian partner and ministries.

\section{Phase 3: Large-Scale Program and Program Profile}

In March 2015, PTL and the in-country partner, RESH, were awarded a grant from the United Nations Children's Fund (UNICEF). This grant funded a large-scale community-based psychosocial support expressive arts program, which was based on the success and lessons learned of Phase 1 and Phase 2. This phase began in June 2015 and completed November 2015. During Phase 3, the American PTL cofounder/trainer returned to Liberia to assist the RESH and PTL partnership development and program implementation.

\section{Activity Development}

The American PTL clinical team developed additional activities for the activity guide. PTL continued to follow CBPR methods and asked the community to act as cultural experts to adapt the activities for cultural context. Examples of adaptations were soccer being substituted for "football," yoga being called "Jackie Chan Karate" due to the children's experience of watching Jackie Chan on television, clinical terms for emotions and psychosocial symptoms being modified for colloquial constructs (with anger becoming vexed and heated, sorrow becoming much crying or saddened, and abusive becoming hitting and beating on). The activities were initially written in American-English but then adapted into Liberian-English by the RESH and PTL team. The format of the activities and training was simplified to model a teacher's lesson plan, where each activity included a purpose, goals, objectives, warning/caution, intended age group, individual and group environment appropriateness, and stepby-step instructions. Figure 1 is a logic model that visually highlights Phase 3's implementation inputs, activities, outputs, short-term and long-term outcomes, and data sources. 
PTL Liberia - Logic Model

\begin{tabular}{|c|c|c|c|c|}
\hline $\begin{array}{l}\text { INPUTS } \\
\text { Program Clinical Team } \\
\text { - } \begin{array}{l}\text { Program development based } \\
\text { on best practices in mental } \\
\text { health and expressive arts } \\
\text { therapies }\end{array} \\
\text { - Program support } \\
\text { Liberian Ministries } \\
\text { - Provided guidance, } \\
\text { opportunities, and cultural } \\
\text { support } \\
\text { Ebola Survivor Network } \\
\text { - Provided support, guidance, } \\
\text { and access to female } \\
\text { survivors } \\
\text { International Nonprofits } \\
\text { - Provided guidance and } \\
\text { opportunity to work in ICC } \\
\text { UNICEF } \\
\text { - Funding for large scale } \\
\text { project }\end{array}$ & $\begin{array}{l}\text { ACTIVITIES } \\
\text { - Psychosocial } \\
\text { expressive arts } \\
\text { training, } \\
\text { programming, and } \\
\text { activities: } 5 \text { month } \\
\text { (TG1) and } 3 \text { month } \\
\text { (TG2) } \\
\text { implementation } \\
\text { - Mental health } \\
\text { advocacy at } \\
\text { ministry meetings } \\
\text { during and after } \\
\text { crisis } \\
\text { - Family support } \\
\text { conversations with } \\
\text { affected families } \\
\text { - Community } \\
\text { outreach and } \\
\text { advocacy }\end{array}$ & $\begin{array}{l}\text { OUTPUTS } \\
\text { - Trained PTL } \\
\text { facilitators } \\
\text { - Employment and } \\
\text { empowerment for } \\
\text { female Ebola } \\
\text { survivors } \\
\text { - Children learn } \\
\text { coping skills, } \\
\text { relationship } \\
\text { building, and } \\
\text { emotional } \\
\text { communication } \\
\text { - Family support } \\
\text { sessions } \\
\text { - Children receive } \\
\text { emotional support } \\
\text { and play time } \\
\text { - Families witness } \\
\text { programming and } \\
\text { child specific } \\
\text { activities }\end{array}$ & $\begin{array}{l}\text { SHORT-TERM } \\
\text { OUTCOMES } \\
\text { (Following } \\
\text { Program) } \\
\text { - PSSs decrease } \\
\text { - Positive } \\
\text { response from } \\
\text { children and } \\
\text { facilitators }\end{array}$ & $\begin{array}{l}\text { INTERMEDIATE } \\
\text { OUTCOMES } \\
\text { (1 year) } \\
\text { - PTL trained } \\
\text { facilitators } \\
\text { continue to } \\
\text { volunteer } \\
\text { their skills in } \\
\text { the } \\
\text { community }\end{array}$ \\
\hline $\begin{array}{l}\text { RESH } \\
\text { - Partnership } \\
\text { - Program support and } \\
\text { implementation } \\
\text { - PSS workers } \\
\text { - } \text { Data collection } \\
\text { - Hired and trained PTL } \\
\text { facilitators } \\
\text { Community } \\
\text { - Program space } \\
\text { - Support and guidance }\end{array}$ & & 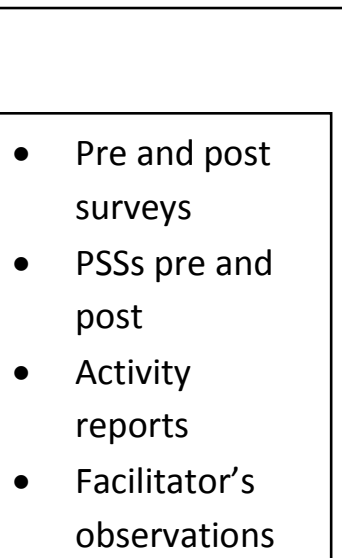 & 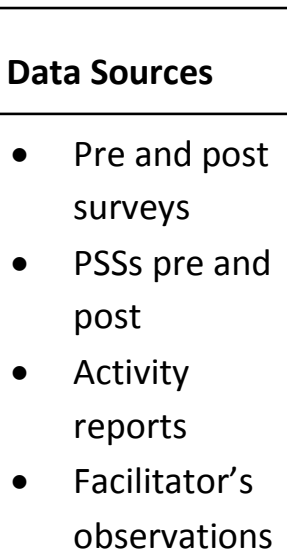 & $\begin{array}{l}\text { - Qualitative } \\
\text { reports }\end{array}$ \\
\hline
\end{tabular}

Figure 1. Playing to Live! (PTL) Phase 3 Logic Model. ICC = interim care center; UNICEF = United Nations Children's Fund; RESH = Renewed Energy Serving Humanity; TG = Treatment Group; PSS = psychological stress symptoms. 


\section{Program Staff}

During this phase, the PTL program extended its staffing. The original project director and project associate continued in a management and supervision role. RESH hired two licensed mental health clinicians in-country to work with the PTL staff to further modify and adapt the original program. The two PTL and two RESH employees made up the supervision and management team. Their role was to oversee the large-scale program and lead the data collection, monitoring, and evaluation. Forty female EVD survivors were hired to work part-time as PTL facilitators in their respective communities, facilitators were selected from a pool of 100 candidates in a process involving the MOHSW/MOGD, the RESH/ PTL team, and the American PTL trainer, with the input from the Ebola Survivor's Network-Liberia. The criteria for a PTL facilitator during the PTL/ RESH implementation included: being a registered EVD survivor, a female, ability to read and write, experience working with children, no current formal employment or source of income, and a MOHSW recommendation. These selected facilitators implemented the PTL play and expressive arts programming in their personal communities, all of which were former Ebola hot zones. None of the 40 PTL facilitators were trained clinicians, and they received the PTL training, additional training from RESH, and ongoing mentoring and supervision from the management team throughout the implementation period.

Additionally, 40 RESH trained employees were selected by RESH to be partnered one-on-one with the 40 PTL facilitators. The majority of RESH employees held licensure or college training in social work, though the exact number of RESH employees with college training was not documented. The 40 RESH employees were referred to as PTL psychosocial support workers (PSW workers). The program trainers and managers carefully distinguished their roles as nonclinicians and their inability to conduct clinical actions.

Their primary roles and responsibilities included monitor and support the PTL facilitator as they worked with the children, monitor for any issues of child neglect to the MOHSW/MOGD, and provide weekly supportive talks and training on childcare and child rights to the primary parent or guardian of the children. In addition to these roles, the PSWs monitored the household conditions and the relationship quality between the parent/caregiver and child and promoted a nurturing and supportive environment through weekly visits to the community. They supported families by teaching trauma informed child care and would report any unsafe living conditions to the ministries.

It was suggested by the Liberian Ministries to the RESH and PTL team to contract mostly women as facilitators due to cultural reasons. In Liberia, traditionally, it is not acceptable for an unfamiliar male to enter a home with women without the man of the house present. In contrast, it is more acceptable to have a woman enter the house and interact with the mother and child following an introduction and permission from the community leader. The RESH PSW was typically not a community member, so the PSW would follow the guidelines of being introduced by the community's elder or religious leader prior to beginning work. As stated, the PTL facilitator was from the community, but due to their EVD survivor status and the stigma that surrounded their status, a RESH and PTL staff or MOHSW community health team member would have to visit the community leaders to explain their work and seek permission and support to conduct the program.

The final roster of the 40 PTL facilitators and 40 RESH PSW was submitted to the MOHSW, MOGD and Ebola Survivors' Network for authorization before project implementation and as part of grant submission for UNICEF. This selection process alone took nearly 2 months to complete. 
PTL facilitators attended a 3-day PTL training from PTL staff and RESH supervisors. Facilitators were provided an activity book and trained and supervised in how to deliver individual activities with children from purposefully-selected households affected by EVD. This training including ongoing mentoring and three repeated capacity development trainings.

\section{Programming}

PTL and RESH chose to work in the chosen PTL facilitators' communities to minimize unsafe travel, target communities in confirmed EVD hot zones, and build community support and reintegration of the EVD survivors turned facilitators, who were highly marginalized and stigmatized in their own communities. Approximately 870 children (ages 3-18 years old) within the 40 selected communities were selected as participants and received the intervention which included play and art activities from the PTL facilitator. Inclusion criteria for children participants included residency in the community and caregiver approval. Data collection categorized each child's experience with EVD as the following: survivor, experienced EVD at home, or experienced EVD in the community.

The PTL facilitator conducted activities at least three to four times per week with groups averaging 15-25 children; the maximum group size was 40 children. Activities were either conducted in an open and central location in the community or in an open location close to the most affected households. This depended on the setup of each individual community. Both types of locations were chosen to provide easy access for children to engage and guardians to observe programming. At each children's activity, at least one or more parents or guardians attended to both help the PTL facilitators as well as actively take part in group activities with their children to foster bonding.

The 40 RESH PSW partnered individually with each facilitator in the communities monitored the conditions of the households and engage in supportive talks with the parents/guardians of the children affected by EVD. The partnered RESH employee to the individual PTL facilitator would provide weekly visits to the community to offer individual and family supportive talks sessions and training in childcare and child rights to the head of the households, also known as "caregivers." A total of 160 caregivers received these services during the implementation period. The PSW repeatedly tracked children's individual case histories and reported to the MOHSW any at risk cases of neglect or needed intervention. Additionally, RESH and PTL supervisors traveled to each community at least once a month to provide guidance, quality control, and monitoring of the PSW.

Close attention was given to supporting the psychosocial needs of the contracted PTL facilitators. Female EVD survivors demonstrated a significantly higher psychological stress symptoms (PSSs) compared to their community peers (Hanson, Decosimo, \& Quinn, 2016). For this reason, all PTL facilitators received ongoing frequent assessment of psychosocial needs, supportive talks, and support for strengthening coping mechanisms by clinicians connected to RESH. During the final 2 months of implementation, the PTL facilitators were given life skills and planning, which focused on preparing them for entry into the workforce or income generating skills.

\section{Treatment Design and Data Collection}

Due to ethical considerations of withholding treatment from identified children, there was no control group but instead a two-treatment group design, where one treatment group began 2 months after the implementation of programming for the first treatment group. Each community was put into a hat and randomly chosen for either treatment group. In TG1, 60\% $(n=533)$ of the children eligible received PTL's play and art activities for 5 consecutive months. TG2, which was the remaining $40 \%$ 
$(n=337)$ of children, received PTL programming for 3 consecutive months starting 2 months after TG1. The rationale for the delay in programming for $40 \%$ of beneficiaries was twofold: (a) phased implementation for quality programming and (b) comparative analysis of program impact on children.

Monitoring and evaluation tools included the Government of Liberia case management tracking form, PTL case tracking form with PSSs, PTL activity form, site visit observation and mentoring form, parent/guardian interview, and training assessments. The Government of Liberia and PTL case tracking forms were collected prior to TG1 and TG2's implementation. The PTL facilitators were required to present an activity form for every activity implemented with their group of children. There were seven PSSs that were assessed from every child $(N=870)$ before each treatment group's implementation. The PSSs were then reassessed within a week of TG1 and TG2 ending. The data for the PSSs were verified using a triangulation method, which used observation and interviews with multiple people in the child's life. An example would be if a child reported bed wetting, the PSW would ask the caregiver and then ask to see the bed. If a symptom could not be verified through this process, then it would not be included in the data entry (Hanson et al., 2016).

A random selection, through the method of selecting community names by a hat, was performed to choose which community would receive an endpoint assessment $(N=356)$. By having a shorter treatment timeframe of the second treatment group, impact change in demonstrated PSSs could be investigated, providing support for whether a longer treatment yields higher levels of positive change over time. Due to lack of resources, a midpoint was not obtained and only baseline and endline data on PSSs were collected, which caused limitations in analyzing true significance of program intervention.

\section{Qualitative Activity Data From Phase 3}

The activity data during Phases 1-3 varied depending on time, resources, and organization capacity. While knowledge was gained during Phase 1 and Phase 2 of programming was utilized to build an effective and sustainable Phase 3, there was limited time and monetary resources to build an indepth process evaluation.

In Phase 3 PTL facilitators were required to fill out an activity report following each activity with the child beneficiaries. The activity reports included the name of the community, the activity used, date of activity, size of group, ages and gender of children involved, a Likert scale from 1 to 5 of facilitators' view of success, two quotes from the children, and qualitative observations from facilitators. The Likert scale had five descriptions of quality, to which the facilitators could choose based off their perception of the success of the activity. The four description words beginning from least favorable included (1) poor quality, (2) fair quality, (3) good quality, and (4) excellent quality.

Approximately 500 activity cards were collected, though, due to limited data entry resources, a total of 127 were blindly selected across both treatment groups for data entry. This was selected by choosing one out of every four activity reports at random. Treatment group was not noted on the cards, so the following activity analysis does not reflect a comparison of the two groups.

The two categories of qualitative data were facilitators' perspectives and participant quotes. Facilitators' perspectives were derived from the qualitative section of each activity report where the facilitators were asked to reflect on the activity, their observations, any recommendation they had. 
Participant quotes were derived from two open ended quotes gathered from different child participants during the activity implementation. All data collected was anonymous. The study received support from the Liberian ministries and an exemption and expedited review, of Form 129 on July 8, 2016, for secondary data analysis under the University Institutional Review Board for the protection of human subjects.

\section{Analysis of Activity Data From Phase 3}

Analysis of activity data was completed on the data collected during Phase 3. A mixed-methods analysis was performed to evaluate the process of Phase 3's implementation. Using SPSS, descriptive statistics were analyzed from Phase 3's randomly selected 127 activity reports, including calculating averages of the participant population represented in the activities. Additionally, analysis was conducted to evaluate the percentage of each Likert scale response and to evaluate the frequency each activity was used in the 127 reports. A qualitative analysis of these reports was employed to analyze the perceptions of the facilitator and participants with the aim to illuminate the process of implementation in a crisis situation by obtaining a snapshot of the implementation.

A grounded theory approach was used to thematically analyze and derive themes among the openended facilitator and participant quotes (Thyme, Wiberg, Lundman, \& Graneheim, 2013). Thyme et al. (2013) described grounded theory as a structured qualitative approach for theme progress and analysis. Rasmus (2014) stated that a traditional grounded theory approach theory develops directly from the data.

For this analysis, two analyzers independently reviewed the qualitative portions of the activity reports and derived specific themes from the data. Results were compared and the analyzers formulated a final analysis of themes and subthemes to gain interrater reliability. The goal for the two analyzers was to derive repeated themes directly from the quotes to highlight the perspectives of the facilitators and participants.

\section{Results}

\section{Group Composition via Activity Reports}

Table 1 summarizes group composition characteristics from the 127 activity reports analyzed. Seventeen PTL activities were represented in the 127 reports. The group composition results paint a picture of what a typical activity implementation was like. The results indicate similarity between the 127 activities, and a fair distribution of ages and genders.

Table 1. Description of Child Participants Represented by 127 Activity Reports

\begin{tabular}{lc}
\hline Number of Children & $M(S D)$ \\
\hline Children per group & $23(1.99)$ \\
Females per group & $13(2.39)$ \\
Males per group & $10(2.32)$ \\
Mean number of children 4-8 years old & $8(2.35)$ \\
Mean number of children 9-12 years old & $9(3.07)$ \\
Mean number of children 13-17 years old & $6(2.65)$ \\
Mean number of children with disabilities & $0(0)$ \\
\hline
\end{tabular}


The facilitators' reports provided the following information on the quality of each activity, which is represented in Table 2: $0 \%$ poor quality, $16 \%$ fair quality, $70 \%$ good quality, and $14 \%$ excellent quality. The quality reporting question was not quantified, so it should be noted that the selection was subject to the facilitator's perception of the wording: poor, fair, good, and excellent. Table 3 outlines the PTL activities represented, the expressive art technique used, and the frequency with which they are represented in the 127 reports analyzed. While the quality reporting question relied on the facilitator's perception of the wording, it appears that there was a reasonable degree of satisfaction towards the activities that were implemented.

Table 2. Results From Likert Scale of Facilitator's Ratings of Activities

\begin{tabular}{lc}
\hline Facilitators' Report & Percentage $(S D)$ \\
\hline Poor quality & $0 \%(0)$ \\
Fair quality & $16 \%(0.37)$ \\
Good quality & $70 \%(0.46)$ \\
Excellent quality & $14 \%(0.35)$ \\
\hline
\end{tabular}

Table 3. PTL Activities From 127 Activities Reports

\begin{tabular}{lcc}
\hline & Category of Expressive Art & $N(\%)$ \\
\hline Activity Name & Technique & $27(21.3 \%)$ \\
My positive future & Play & $23(18.1 \%)$ \\
Parachute play floating & Art & $22(17.3 \%)$ \\
Musical freeze dance & Play & $17(13.4 \%)$ \\
Super hero & Play & $10(7.8 \%)$ \\
Healing hands & Art/play & $6(4.7 \%)$ \\
Your favorite place & Yoga & $5(3.9 \%)$ \\
My favorite memory & Art & $4(3.2 \%)$ \\
Magical power & Art & $3(2.4 \%)$ \\
Favorite memory & Play & $2(1.6 \%)$ \\
Strong trees & Art & $2(1.6 \%)$ \\
Dancing & Yoga & $1(0.8 \%)$ \\
Drawing & Dancing & $1(0.8 \%)$ \\
Peaceful place & Art & $1(0.8 \%)$ \\
Power sticks & Art & $1(0.8 \%)$ \\
Stand proud & Play & $1(0.8 \%)$ \\
Football & Play & $1(0.8 \%)$ \\
\hline
\end{tabular}

\section{Facilitator Perceptions From Activity Reports}

The categories that resulted from the entries of the facilitator's perceptions of the process are as follows: (a) observed participant emotions, (b) barriers to attendance, (c) observed participant behavior, (d) observed participant reactions, and (e) facilitator recommendations (Table 4). 
Table 4. Facilitator Perspectives From 127 Activities

\begin{tabular}{lc}
\hline Theme & Times It Was Mentioned, $N(\%)$ \\
\hline Observed participant emotions & $29(22.8 \%)$ stated the children were happy \\
& $6(4.7 \%)$ stated the children were sad \\
Barriers to attendance & $37(29.2 \%)$ talked about barriers \\
Observed participant behavior & $58(45.7 \%)$ talked about the children being \\
& active/working \\
& $8(6.3 \%)$ talked about the children being \\
& inactive/disruptive \\
Observed participant reactions & $7(5.5 \%)$ spoke about positive reactions from the children \\
Recommendations & $23(18.1 \%)$ gave recommendations including providing \\
& food, school fees, and books for adolescents \\
\hline
\end{tabular}

\section{Observed Participant Emotions}

This category of response was divided into two sections, happy and sad. There were $29(22.8 \%$ of a total of 127) entries, where the facilitators observed the children as happy. A few examples of these observations are "I observe all the children were laughing and happy during the play"; "I observed happiness, unity, and love developing among the children at the Community"; and "I observed that dance make the children feel good and happy." There were six (4.7\%) entries where the facilitators observed the children as sad. A few examples of these observations are "I observed that two of my children in my group was not well;" "I observe that some of the children were not happy because they are not in school"; and "I observe that this activity look sorryful, the reason is when the children explaining how want to be in the future they can share tears the reason it they think about her parents."

\section{Barriers to Attendance}

There were 37 (29.2\%) quotes about barriers the children faced in attending the PTL activities. The barriers observed included (a) other responsibilities (cooking and chores, studying and school), (b) weather preventing the children from attending, (c) children and caregivers forgetting about the program, (d) the children being sick, (e) traveling, and (f) feeling weak from hunger.

\section{Observed Participant Behavior}

This category was divided into two categories: active/working and inactive/disruptive. There were 58 (45.7\%) quotes specific to the children being active/working during the activity. A few examples of these quotes are "The play went on very fine it was just fun been with the children today"; "I observe that the children love the play and want to be around every time"; and "I observe this week that all of my 23 children are starting to understand each other. Once they are understanding each other that mine, we are on cause." There were eight (6.3\%) quotes specific to the children being inactive/disruptive. A few examples of these quotes are "I observe the children hitting on one another" and "I observe the children standing, but was difficult for them stand without holding anything."

\section{Observed Participant Reactions}

There were seven (5.5\%) quotes specific to the children's reactions to the activity and program. A few examples of these quotes are "I observe that most of the children want to join the program"; "that this game make my children create social team work"; and "I observed that this play is very important, it make the children forget their negative thinking." 


\section{Facilitator Recommendations}

There were 23 (18.1\%) facilitators who provided recommendations for the programming. The recommendations included providing food for the children, providing medical help, providing school fees, continuing programming, continuing specific activities, adding books and storytelling for adolescents, and that every activity should be repeated.

\section{Child Participant Quotes From 127 Activity Reports}

The activity reports instructed the facilitators to gather two quotes per activity from the participants. The themes derived from the quotes were (a) emotions, (b) desires, (c) feelings toward product and outcome, and (d) feelings about activity and reflections on specific activity (Table 5).

Table 5. Child Quotes From 127 Activity Reports

\begin{tabular}{lc}
\hline Theme & Times It Was Mentioned, $N(\%)$ \\
\hline Emotions & $23(18.1 \%)$ reflected positive emotions, mainly using the \\
& word happy \\
Desires & $18(14.2 \%)$ talked about desires; this theme reflected hope \\
& for the future, self-esteem, and a desire to be \\
& surrounded by friends \\
Feelings toward product and & $17(13.4 \%)$ reflecting on their art and play; all quotes had a \\
outcome & positive theme \\
Feelings about activity and & $111(87.4 \%)$ quotes related to the child's feelings and/or \\
reflections on specific & reflections on a specific activity; the quotes included in \\
activity & this theme reflect positivity, active participation, and \\
& enjoyment \\
\hline
\end{tabular}

\section{Emotions}

There were 23 (18.1\% of a total of 127) quotes that contained emotional words. Examples of quotes were "When we move fast we feel happy like the water chasing after us; we were excited during this activity"; "This play make us to feel good, because we share our comfort"; "I am happy because I am playing with my friends." All 23 quotes reflected positive emotions, mainly using the word happy.

\section{Desires}

There were 18 (14.2\%) quotes that matched the theme desires. This theme reflected hope for the future, self-esteem, and a desire to be surrounded by friends. Examples of these quotes are "They said we should continue the play; we should continue"; "I love to be a nurse working in the clinic; I went to achieve my own house in future"; "We want to be here so we can be talking story"; and "We believed that our future can be positive if we study to be a doctor. We also want to be a driver to take people to where they want to go on time or a nurse to help save lives."

\section{Feelings Toward Product and Outcome}

There were 17 (13.4\%) quotes reflecting on the product produced from the activity or the outcome. All the quotes had a positive theme, which included themes of hope, self-esteem, being proud of what they created, and relationship building. Examples of these quotes are "The child say that this my positive future make them feel important"; "I enjoy the sound of difference instruments put together"; "This child say she love this play because it make her feel better for the future. This child say he love this play because he want to be a doctor"; and "I love my positive future because it make me image about my future; I draw my positive future of life." 


\section{Feelings About Activity and Reflections on Specific Activity}

There are 111 (87.4\% of a total of 127) quotes related to the child's feelings and/or reflections on a specific activity. The quotes included in this theme reflect positivity, active participation, and enjoyment. There was one nonpositive quote that stated, "I do not like this play." Examples of these quotes are "My favorite is when the doctor told me that he is discharging me from the ETU"; "She said that she like the two session; The children say that they always feel good in this session"; "The children says they love the play; This play positive play is very good"; and "She love the program."

\section{Activity Usage and Description}

It is unclear whether the frequency of the activities represented on Table 3 is an accurate portrayal of the facilitators favoring certain activities or indicates that choosing one in every four-activity report turned in is not an effective technique for choosing an accurate sample.

According to Table 3, the story telling activity represented 27 of the 127 reports. During the cultural adaptation process, the Liberian stakeholders told the PTL clinical team that story telling was an important part of Liberian culture. PTL created an activity that reflected supportive communication techniques that could be used during storytelling, and the Liberian PTL/RESH team chose Liberian books and stories for the facilitators to use. The activity my positive future was represented in 23 of the 127 activities. This activity uses art therapy techniques, where children were instructed to visualize and create an image of something positive that will be in their future. The aim behind this is for the child participants, who have recently experienced trauma to create a concrete image of their desires for the future. As a group, they were then asked how they could achieve this future and received support from their peers.

Parachute play floating and musical freeze dance were also represented as activities used frequently. These activities are derived from theories of play therapy. These two activities ask the children to work together to mirror each other's movements, work together for a common goal, and work together as a team. During the epidemic, people were afraid to be close to others. High levels of fear and isolation were observed by the PTL team. These activities aimed to support children in recreating relationships with peers and mentors.

The super hero activity, which was represented in 10 out of the 127 activity reports reviewed, is derived both from art therapy and play therapy. Children are instructed to create a super hero cape and draw images on the cape that reflect their interpersonal strengths. The children were then encouraged to wear the capes and act out their super hero personality. During the implementation of this activity, PTL received feedback that the concept of superhero was not culturally understood. The facilitators called it "magical juju," because super heroes as a concept is less prevalent among children, particularly those in less urban centers with limited access to foreign television movies. PTL's Liberian facilitators individually chose culturally appropriate terminology to match the aims of the activity. The activity's aims were to support the children to visualize and create images of their individual strengths, and additionally, the facilitators were instructed to support the children in exploring these strengths through play and interaction with peers. 


\section{Discussion}

While PTL started with two Americans, it focused on looking to the Liberian community as the primary guide to program implementation. The three phases of programming would not have been possible without the consistent guidance of the diverse Liberian stakeholders.

Throughout the three phases of programming, the PTL team noted the positive reaction to play and expression from the facilitators, participants, families, and the communities involved. This supports the art therapy theory that by engaging in art making an individual becomes intrinsically aware of their creative identity, which in turn begins to strengthen the individual's emotional and cognitive recovery (Van Lith, 2015). While facilitators' roles were to instruct and support the children through the activities, they themselves were encouraged to engage in an artistic process. Thus, building on the theory that art making in a group not only builds on the emotional and cognitive healing but also increases physical, social, and cognitive growth (Pretorius \& Pfeifer, 2009).

Of note, while the theory of art therapy built the foundation for understanding the impact of creativity on stress caused by trauma, the facilitators were trained as art and play supporters and not clinical therapists. The activities and training highlighted art as a mechanism to support children and community healing but not for trauma processing or clinical mental health recovery (Kalmanowitz \& Potash, 2010).

\section{Findings From the Activity Reports}

PTL's clinical team recommended approximately 20-25 children participants in each activity. The results from the group composition statistics indicate that the group participation numbers matched this recommendation, where a mean of 23 children participated in each activity. This indicated that the activities were well attended and supports the idea that children and families enjoyed the programming.

The participant and facilitator quotes provided by the activity reports indicate a positive reaction to the activities and programming. The children appear to gain positive reflections and interactions with peers and facilitators, and enjoy the process and product of the activities. The quotes seem to paint a picture of group cohesion, while also indicating that a shift from negative to positive attitudes occurred. The quotes match the individual activity's goals, which were to support the child to rebuild relationships, build coping skills, and find enjoyment (Pretorius \& Pfeifer, 2009; Van Lith, 2015).

Barriers that should be taken into consideration are the request for food and basic needs support. Maslow's hierarchy of needs is a theory that states an individual must attain certain levels of needs before they can reach self-actualization (Ruchiwit, 2013). The first level of needs includes items necessary for survival, which would reflect the facilitator's suggestion for food. The second level of needs includes safety. While this typically refers to shelter and a safe environment, one the goals of PTL is to rebuild a child's emotional safety through providing skills to local leaders and rebuilding healthy relationships (Ruchiwit, 2013).

Though PTL is specifically focused on psychosocial programming, it is important to work within the stated needs of the community. This can be done by working with other entities in the community who may be able to fill the need. The activity reports from this project were received after the 
program was finished, so PTL was unable to build follow-up support or ask questions to gain a more in depth understanding of the program in real time.

Future steps for PTL include building a feedback loop between facilitators, supervisors, in-country partners, and PTL clinical staff during program implementation. This feedback loop would provide opportunities to build follow-up trainings to meet gaps in skills, use a more in-depth process evaluation steps, and evaluate if the activities are meeting the intended therapeutic goals. Murray et al. (2011) advocated for an apprenticeship model when hiring nonmental health clinicians, where mental health clinicians and supervisors consistently support the nonclinician's work through ongoing training and coaching, quality control, monitoring the program, and direct supervision. Incorporating this model into PTL program model will provide a greater opportunity for informed program development and capacity building in future programming.

\section{Limitations}

Due to the nature of crisis and epidemic, there were limitations and barriers to program implementation and data collection. While PTL staff made every attempt available to work with the Liberian Ministries and communities, a formal needs and resource assessment was not performed. This was in part due to the urgency of the situation, safety concerns for data collectors working in potential hot zone, limited financial and personnel resources, and PTL's limited structural foundation for evidence-based assessment tools.

Following a review of lessons learned from all three phases in Liberia, PTL has identified tools for future use. Practical assessment tools are important as they guide implementers in understanding the context of the community's needs, resources, and cultures (WHO \& United Nations High Commissioner for Refugees, 2012). Assessing Mental Health and Psychosocial Needs and Resources (WHO \& United Nations High Commissioner for Refugees, 2012) is an example of a practical toolkit for performing a rapid needs assessment prior to implementations. This toolkit provides step-by-step tools to help program developers build understanding and relationships within the community they have targeted to work within. This would be a beneficial tool to utilize in the future when less limitations restricted use.

Due to financial, time, and personnel barriers for the assessment tools, Phases 1 and 2 of PTL programming did not have a formal monitoring and evaluation process. Therefore, it is difficult to truly show the impact of the ICC and community based pilot programs. While the qualitative results of Phase 3 begin to paint a picture of the daily programming and the children's responses, there is a limit to understanding the facilitators' knowledge gain and needs specific to the programming and training. The question about quality within the activity reports was not quantified, so the facilitators were left to choose an answer based on their own perceptions of the wording, which could have caused issues with fidelity. The facilitators received ongoing psychosocial support training from RESH and PTL, though it is unclear what techniques and knowledge were sustainable and understood.

While PTL's program focus was on children, the Ebola survivors, who were hired as facilitators, had also experienced significant trauma and loss. PTL and RESH organized support groups and professional development, but a future goal will be to provide dedicated therapeutic support to the facilitators/caregivers. Support for caregivers working in a trauma environment is important. A trauma survivor who is working within the trauma environment is more susceptible to more severe 
trauma symptoms, compassion fatigue, and burnout (James, Noel, \& Roche Jean Pierre, 2014). Research on the effects of working as a caregiver in a trauma environment has been heavily focused on clinicians, though nonclinicians are at high risk for secondary traumatization and amplified trauma symptoms due to closer proximity to the emergency environment, longer hours, and less education and experience (James et al., 2014).

\section{Best Practices for Process Evaluation}

Next steps in future implementation in emergency settings will be to follow best practices for setting up foundations for a process evaluation from the first connection with the community. Best steps forward in future programming for PTL will include having a process evaluation foundation that can be flexible for cultural and logistical adaptions. A well-implemented process evaluation will provide an in-depth review of the development and implementation of a program. The process evaluation should be able to clearly state multiple facets of a program (Moore et al., 2005). Key process elements include evaluating effectiveness of training and programming, perceptions of the trainees, satisfaction of the trainees, perceptions of the community, if the program was implemented appropriately and if the intended goals were met (Nakkash et al., 2012). Evaluation methods for a process evaluation would include pre-and posttests from trainings, evaluation of the CBPR approach (Goodwin et al., 2003), observation tools, a facilitator satisfaction evaluation, focus group notes, log sheets, focus group notes, cultural adaptation notes, assessments evaluating the programming throughout the implementation, and others (Nakkash et al., 2012). PTL's development, implementation, and research target multiple systems, including: engaging with the community, following the community's guidance, training local nonclinicians, programming for children, and accessing families. With all the moving parts within this framework, it is imperative to have a strong evaluation groundwork to evaluate the impact and quality of the programming.

\section{Conclusion}

PTL's presence in Liberia began in October 2014 and finished its last project December 2015. In a little over a year, PTL implemented three psychosocial expressive arts programs in Liberia and developed a foundation for future global work for the organization. The core values of PTL were to follow the guidance of the Liberian people, promote community based psychosocial programming, and promote play and expression as a healing technique to a crisis. The qualitative results indicate the children found enjoyment out of the art and play, being with peers, and receiving support by an adult. The quotes and observations indicate that hope and self-esteem increased among the children. The facilitators' ratings and observations implied satisfaction with the programming and specific activities but concern for the overall well-being of the children. Barriers to the success of the program were also indicated, including concerns related to hunger, chores, and illness. Future steps based off the Liberian implementation for PTL include a comprehensive needs, resource, and literature assessment protocol to ensure congruence with the community and active players in the crisis response, continued literature review on evidence based practice for mental health lay clinicians, further integration of community based participatory research, and continued growth in monitoring and evaluation practices. 


\section{References}

American Psychiatric Association. (2013). Diagnostic and statistical manual of mental disorders (5th ed.) Washington, DC: Author.

Banbury, N. M. (2016). Case study: Play therapy and eye movement desensitization and reprocessing for pediatric single incident posttraumatic stress disorder and developmental regression. International Journal of Play Therapy, 25, 166-174. http://doi.org/10.1037/pla0000026

Berkowitz, S. J., Stover, C. S., \& Marans, S. R. (2011). The Child and Family Traumatic Stress Intervention: Secondary prevention for youth at risk of developing PTSD. Journal of Child Psychology and Psychiatry, 52, 676-685. http://doi.org/10.1111/j.1469-7610.2010.02321.x

Briggs-Gowan, M. J., Carter, A. S., Clark, R., Augustyn, M., McCarthy, K. J., \& Ford, J. D. (2010). Exposure to potentially traumatic events in early childhood: Differential links to emergent psychopathology. Journal of Child Psychology and Psychiatry and Allied Disciplines, 51, 1132-1140. http://doi.org/10.1111/j.1469-7610.2010.02256.x

Bremner, J. D., Randall, P., Vermetten, E., Staib, L., Bronen, R. A., Mazure C., ... Charney, D. S. (1997). Magnetic resonance imaging-based measurement of hippocampal volume in posttraumatic stress disorder related to childhood physical and sexual abuse: A preliminary report. Biology Psychiatry, 41, 23-32.

Casey, G. (2015). Ebola: The facts. Kai Tiaki Nursing New Zealand, 20, 20-25.

Cohen, S., Janicki-Deverts, D., \& Miller, G. E. (2007). Psychological stress and disease. JAMA, 298, $1685-1687$.

Coholic, D., Eys, M., \& Lougheed, S. (2012). Investigating the effectiveness of an arts-based and mindfulness-based group program for the improvement of resilience in children in need. Journal of Child and Family Studies, 21, 833-844. http://doi.org/10.1007/s10826-011-9544-2

Escandón, S. (2014). Using the life course framework and CBPR to develop culturally competent interventions. Issues in Mental Health Nursing, 35, 144-147. http://doi.org/10.3109/01612840.2013.819597

Foa, E. B., Riggs, D. S., Dancu, C. V., \& Rothbaum, B. O. (1993). Reliability and validity of a brief instrument for assessing post-traumatic stress disorder. Journal of Traumatic Stress, 6, 459473. doi:10.1002/jts.2490060405

Foa, E., Cashman, L., Jaycox, L., \& Perry, K. (1997). The validation of a self-report measure of PTSD: The Posttraumatic Diagnostic Scale. Psychological Assessment, 9, 445-451.

Hanson, J. E., Decosimo, A. C., \& Quinn, M. A. (2016). Diminished quality of life among women affected by Ebola. Journal of Social, Behavioral, and Health Sciences, 10, 112-133. http://doi.org/10.5590/JSBHS.2016.10.1.11

Hayden, E. C. (2014). Ebola's lost ward. Nature, 513, 474-477. Retrieved from https://www.nature.com/polopoly_fs/1.15990!/menu/main/topColumns/topLeftColumn/pdf/513 474a.pdf

Hugo, M., Declerck, H., Fitzpatrick, G., Severy, N., Gbabai, O. B.-M., Decroo, T., \& Van Herp, M. (2015). Post-traumatic stress reactions in Ebola virus disease survivors in Sierra Leone. Emergency Medicine, 5, 285. http://doi.org/10.4172/2165-7548.1000285 
Gantt, L., \& Tinnin, L. W. (2009). Support for a neurobiological view of trauma with implications for art therapy. The Arts in Psychotherapy, 36, 148-153. http://doi.org/10.1016/j.aip.2008.12.005

Goodwin, D. J., Pluto, D. M., Reininger, B., Francisco, S., Ruff, G., \& Williams, D. (2003). The CENTERED evaluation guide. Columbia, SC: South Carolina Department of Health and Environmental Control.

Gonzalez, C. L., \& Bell, H. (2016). Child-centered play therapy for Hispanic children with traumatic grief: Cultural implications for treatment outcomes. International Journal of Play Therapy, 25, 146-153. http://doi.org/10.1037/pla0000023

Israel, B. A., Schulz, A. J., Parker, E. A., \& Becker, A. B. (1998). Review of community-based research: Assessing partnership approaches to improve public health. Annual Review of Public Health, 19, 173-202. http://doi.org/10.1146/annurev.publhealth.19.1.173

Kaplan, F. F. (2000). Art, science, and art therapy: Repainting the picture. Philadelphia, PA: Jessica Kingsley Publishers.

Kalmanowitz, D., \& Potash, J. S. (2010). Ethical considerations in the global teaching and promotion of art therapy to non-art therapists. Arts in Psychotherapy, 37, 20-26. http://doi.org/10.1016/j.aip.2009.11.002

Kohrt, B. A., Blasingame, E., Compton, M. T., Dakana, S. F., Dossen, B., Lang, F., \& Cooper, J. (2015). Adapting the crisis intervention team (CIT) model of police-mental health collaboration in a low-income, post-conflict country: Curriculum development in Liberia, West Africa. American Journal of Public Health, 105, 73-80.

Kruk, M. E., Rockers, P. C., Williams, E. H., Varpilah, S. T., Macauley, R., Saydee, G., \& Galea, S. (2010). Availability of essential health services in post-conflict Liberia. Bulletin of the World Health Organization, 88, 527-534. http://doi.org/10.2471/BLT.09.071068

Levey, E., Borba, C., Harris, B., Carney, J., Domínguez, S., Wang, E., \& Henderson, D. (2013). Assessment of the needs of vulnerable youth populations in post-conflict Liberia. African Journal of Psychiatry, 16, 349-355. http://doi.org/10.4314/ajpsy.v16i5.47

Moore, G. F., Audrey, S., Barker, M., Bond, L., Bonell, C., Hardeman, W., .. Baird, J. (2015). Process evaluation of complex interventions: Medical Research Council guidance. British Medical Journal, 350, h1258. http://doi.org/10.1136/bmj.h1258

Mouthaan, J., Sijbrandij, M., Luitse, J. S. K., Goslings, J. C., Gersons, B. P. R., \& Olff, M. (2014). The role of acute cortisol and DHEAS in predicting acute and chronic PTSD symptoms. Psychoneuroendocrinology, 45, 179-186. http://doi.org/10.1016/j.psyneuen.2014.04.001

Murray, L. K., Dorsey, S., Bolton, P., Jordans, M. J., Rahman, A., Bass, J., \& Verdeli, H. (2011). Building capacity in mental health interventions in low resource countries: An apprenticeship model for training local providers. International Journal of Mental Health Systems, 5, 30. http://doi.org/10.1186/1752-4458-5-30

Nakkash, R. T., Alaouie, H., Haddad, P., El Hajj, T., Salem, H., Mahfoud, Z., \& Afifi, R. A. (2012). Process evaluation of a community-based mental health promotion intervention for refugee children. Health Education Research, 27, 595-607. http://doi.org/10.1093/her/cyr062

James, L. E., Noel, J. R., \& Roche Jean Pierre, Y. M. (2014). A mixed-methods assessment of the experiences of lay mental health workers in postearthquake Haiti. American Journal of Orthopsychiatry, 84, 152-163. http://doi.org/10.1037/h0099387 
Orr, P. P. (2007). Art therapy with children after a disaster: A content analysis. The Arts in Psychotherapy, 34, 350-361. http://doi.org/10.1016/j.aip.2007.07.002

Pandey, A., Atkins, K. E., Medlock, J., Wenzel, N., Townsend, J. P., Childs, J. E., ... Galvani, A. P. (2014). Strategies for containing Ebola in West Africa. Science, 346, 991-995. http://doi.org/10.1126/science.1260612

Pretorius, G., \& Pfeifer, N. (2009). Group art therapy with sexually abused girls. South African Journal of Psychology, 40, 63-73. http://doi.org/10.1177/008124631004000107

Rasmus, S. M. (2014). Indigenizing CBPR: Evaluation of a community-based and participatory research process implementation of the Elluam Tungiinun (Towards Wellness) program in Alaska. American Journal of Community Psychology, 54, 170-179. http://doi.org/10.1007/s10464-014-9653-3

Ruchiwit, M. (2013). Determinants affecting the well-being of people in the Greater Mekong Subregion countries. Nursing and Health Sciences, 15, 94-100. http://doi.org/10.1111/nhs.12004

Talwar, S. (2007). Accessing traumatic memory through art making: An art therapy trauma protocol (ATTP). The Arts in Psychotherapy, 34, 22-35.

Thyme, K., Wiberg, B., Lundman, B., \& Graneheim, U. H. (2013). Qualitative content analysis in art psychotherapy research: Concepts, procedures, and measures to reveal the latent meaning in pictures and the words attached to the pictures. The Arts in Psychotherapy, 40, 101-107. http://doi.org/10.1016/j.aip.2012.11.007

Van der Kolk, B. (1989). The compulsion to repeat the trauma. Psychiatric Clinics of North America, $12,389-411$.

Van Lith, T. (2015). Art making as a mental health recovery tool for change and coping. Art Therapy, 32, 5-12. http://doi.org/10.1080/07421656.2015.992826

Warson, E. (2012). Healing pathways: Art therapy for American Indian cancer survivors. Journal of Cancer Education, 27, 47-56.

World Health Organization (WHO) Ebola Response Team. (2014). Ebola virus disease in West Africa: The first 9 months of the epidemic and forward projections. New England Journal of Medicine, 371, 1481-1495.

World Health Organization (WHO) Ebola Response Team. (2016). Special report after Ebola in West Africa: Unpredictable risks, preventable epidemics. New England Journal of Medicine, 375, $587-596$.

World Health Organization (WHO) \& United Nations High Commissioner for Refugees. (2012). Assessing Mental Health and Psychosocial Needs and Resources: Toolkit for humanitarian settings. Geneva, Switzerland: WHO. 
The Journal of Social, Behavioral, and Health Sciences is an open-access, peer-reviewed, online interdisciplinary journal focusing on research findings that address contemporary national and international issues. Its objectives are to (a) encourage dialogue between scholars and practitioners in the social, behavioral, and health sciences that fosters the integration of research with practice; (b) promote innovative models of interdisciplinary collaboration among the social, behavioral, and health sciences that address complex social problems; and (c) inform the relationship between practice and research in the social, behavioral, and health sciences.

Walden University Publishing: http://www.publishing.waldenu.edu 